\title{
Care needs of pregnant adolescents: a vision of community health nursing
}

\begin{abstract}
Summary
The present investigation is a qualitative study that aimed to describe and analyze the care needs of the pregnant adolescent and provides the community health nurse. The research question was: What care needs does the pregnant adolescent have? Leonardo Boff is the author who gives theoretical support to research from the perspective of humanist thought. Vera Regina Waldo with her proposal of human care also supported herself. The study involved nine visiting nurses, that is, community care nurses who work in Health Centers of the State of Mexico. The results were obtained through the in-depth interview. The main thematic category is the resonance of the care of life. Sub categories are tenderness, compassion, kindness, caress, and recognizing myself in otherness. The results obtained will contribute in emphasizing that the care/ care provided by the community health nurse is vital for the pregnant adolescent to overcome the physiological, psychological and social stress she faces and achieve a return to her family and social context. The care provided by the nurse went beyond the procedures and institutional protocols for prenatal care, in addition to taking care of the pregnancy as a physiological event, I care for the person, helped her to continue living, protected her and integrated her back into her family context and in some cases to their school context.
\end{abstract}

Keywords: Resonances care, community health nurse, pregnant teen

\section{Introduction}

According to Boff, "care is not an option: we learn to care or perish". And it is that, in effect, as it adds lines after the previous one, the essence of the human being resides in the 'care', which founds a minimum ethic that protects life, social relations and preserves nature. In his own words: "Care has multiple dimensions: taking care of oneself, of the near, of the distant, of the strangers, of the planet, of production, of consumption, etc.". Currently, says the Brazilian, we live in a virtual world, online, which puts at risk the essence of humanity; the societies of knowledge and the current forms of communication separate us, isolate people; Yes, they open new horizons of knowledge, however, they endanger the care for the other and for the earth. But why does this happen?

Apparently Boff, ${ }^{1}$ we live a new paradigm of coexistence characterized by carelessness, indifference and abandonment, whose main hallmark is the lack of care. There is carelessness and indifference towards children, the unemployed, the poor, the disorganized growth of cities and public affairs and social security; but also because of the climate, the soils, the seas and, of course, the families. Faced with this situation, several alternatives have been presented, from religious, technological-scientific, moral and even educational; however, says our author, they have been insufficient, since they have not addressed the root of the problem, which for him is none other than the "loss of connection with the whole: the feeling of belonging to the human being must be returned to the human being. Human family, to the earth, to the universe and to the divine purpose" (Table 1).

In agreement with what has been exposed up to now, Boff ${ }^{1}$ uses, in his necessary Care and following Heidegger, the term "way-of-beingin-the-world", defining it as that which structures the way in which man relates and coexists with the world around him. And, according to him, there are two ways of "being-in-the-world": by the "way-ofbeing-work" and the "way-of-being-care". We will focus on the last, the way to be careful.
Volume 6 Issue 2 - 2019

\author{
Elia Vazquez Chamorro,' Lujan Maria del \\ Pilar Gómez E,² Maria Teresa E Cuamatzi \\ Peñal \\ 'Professor of nursing, Autonomous Mexico State University, \\ Mexico \\ ${ }^{2}$ Research Professor of Nursing, National University of Trujillo, \\ Peru \\ Correspondence: Elia Vazquez Chamorro, Professor of \\ nursing, Autonomous Mexico State University, Mexico, Tel 044 \\ 55 20303905, Email echv99@hotmail.com \\ echamorrov@uaemex.mx
}

Received: August 22, 2017| Published: March 27, 2019
With reference to care, Boff points out that "knowing how to care" is a fundamental learning for the human being, since, if we do not learn to do it, we will disappear as a species. In his own words:

Table I Dimensions of care

\begin{tabular}{|c|c|c|}
\hline Leonardo Boff & Edgar Morin & Martin Heidegger \\
\hline Material dimension & Dimension of Self Care & $\begin{array}{l}\text { Care as root of the } \\
\text { human being }\end{array}$ \\
\hline \multirow[t]{2}{*}{ Spiritual dimension } & $\begin{array}{l}\text { Dimension of Caring } \\
\text { for the Other }\end{array}$ & $\begin{array}{l}\text { Care as mode-of-being } \\
\text { in the world }\end{array}$ \\
\hline & & $\begin{array}{l}\text { Care as a way-of-being- } \\
\text { human }\end{array}$ \\
\hline
\end{tabular}

Source: self made

If there is no care, it will be difficult to achieve sustainability that is maintained in the medium and long term. They are the two basic pillars that sustain the necessary transformation of the way of inhabiting the Earth. But sustainability and care cannot be affirmed if they are not accompanied by a spiritual revolution. Contrary to what skeptics and secularists affirm, spirituality is not a monopoly of religions. To be spiritual is to awaken to the deepest dimension that exists in the human being and that makes him sensitive to solidarity, justice and fraternity. As a human being, we have to realize the urgency and the need to take care of all things, of life and of the Earth, but mainly of human spirituality. ${ }^{1}$

Starting from the construction of the concept of care and the clarification of its cosmological and anthropological foundations, Boff develops a new paradigm of care: that of itself, that of others, that of the body, that of the psyche and that of the spirit, and focuses it particularly on fields such as medicine, nursing and education. Thus, the human being is presented as a biological, social, spiritual and psychological entity immersed in a system whose factors influence their needs and behaviors, either to guarantee health or determine disease.

Indeed, recognizing each other as members of the same species, is only one of the challenges of the humanizing project, achieving it will 
only be possible through the encounter and recognition of the other as different and different from me, but as legitimate and dignified as me. ${ }^{2}$

As for care, it is given when the other is accepted and needed, when the existence of this other is important to me and I even contribute to it. This is when care takes shape and materializes in different ways. But it should be noted that, as Heidegger warns, the phenomenon of care demands a type of intelligence; it is, according to him, a way of being human. In this regard, Maturana ${ }^{3}$ emphasizes the importance of language and conversations, making it notice as an expression of mutual acceptance. Here are his words:

The realization that human beings exist as such in the interweaving of many conversations in many different operational domains that shape many domains of different realities, is particularly significant because it allows us to recover the emotional as a fundamental area of the human. In the evolutionary history, the human is configured with the conversation as the language emerges as a recursive operation in the consensual behavioral coordination's that occur in the realm of a particular way of living in the flow of the commotion of the members of the particular group of bipedal primates to which we belong For this reason, as the conversation arises with the emergence of language in the operational field of mutual acceptance (love) in these primates, the human is founded constitutively with the basic participation of emotion and in particular love. In the fantasy of the patriarchal culture to which we belong in the West, and which now seems to expand across all areas of the earth, emotions have been devalued in favor of reason as if it could exist independently or in opposition to them.

According to what has been written so far, human beings must be careful so that, in turn, they learn to take care of themselves; and with it, in him same impulse of caring is generated. Thus, care appears as a loving, welcoming and enveloping attitude. It has already been said that Boff proposes a new paradigm, which, in fact, determines the essence of the human being: that of caring as an attitude towards oneself, but also towards the world for this is necessary to address the emotional and spiritual dimension of one's own reason and the elements that compose it, since it is probable that, by doing this, it will be possible to better understand the complexity of the human being and the role he must play in the cosmos (Figure 1).

Boff proposes that the human being be guided less by reason and more by his feelings; just like that, he says, we will learn to take care of ourselves, take care of the other and the Earth. Hence the proposal of the 'repercussions of care', understood as the resonances of various important attitudes that arise from care and that are specified in various ways (Table 2 ).

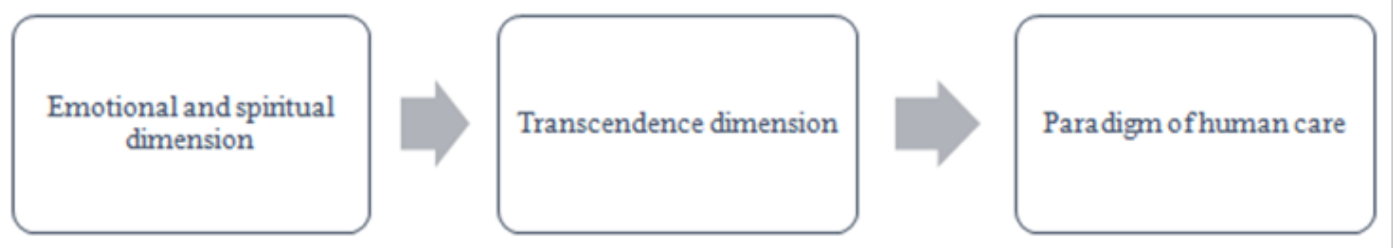

Figure I Dimensions for human existence.

Table 2 According to Boff, I there are seven repercussions of care

\begin{tabular}{|c|c|}
\hline Repercussion & Manifestation \\
\hline Love & It is the feeling of affection and belonging to the same destination and the same historical path. \\
\hline Just measure & $\begin{array}{l}\text { The just measure refers to understanding that each part is within an articulated whole. It's about win-win. It refers to living in } \\
\text { harmony and taking only what is necessary from nature, from the earth, from biology and from science. }\end{array}$ \\
\hline The vital tenderness & $\begin{array}{l}\text { It is the affection that we provide to people and the care that we apply to existential situations. Tenderness is caring without } \\
\text { obsession; It is work of the strength of the heart. The anguish of the other is my anguish. }\end{array}$ \\
\hline The caria essence & $\begin{array}{l}\text { The careness as an attitude of nobility, of good heart, of good feeling for the other, demands total altruism, respect for the } \\
\text { other and renounces any other intention other than that of the experience of wanting and loving. }\end{array}$ \\
\hline $\begin{array}{l}\text { The necessary } \\
\text { conviviality }\end{array}$ & $\begin{array}{l}\text { Generate an ethical, affective and productive bond with oneself, with others and with nature. Balance between what is } \\
\text { produced and consumed, between society and nature. }\end{array}$ \\
\hline $\begin{array}{l}\text { The fundamental } \\
\text { kindness }\end{array}$ & $\begin{array}{l}\text { It refers to the treatment of the other with the heart; is the ability to capture the dimension of present value in people, things } \\
\text { and environment. When something has value for us, it is treated well and taken care of. }\end{array}$ \\
\hline Radical compassion & $\begin{array}{l}\text { The ability to share the passion of the other and with the other. It is about leaving the circle and entering the other's galaxy as } \\
\text { another, to suffer with it, rejoice with it, walk with it and build life in synergy with it. }\end{array}$ \\
\hline
\end{tabular}

In short, caring for the other means establishing a dialogue that, based on an alliance of peace and love, can only be liberating and, of course, never oppressive. For Boff, the above will take on a special aspect under the prism of male-female relations, since it can be understood as an effort to dismantle the structures of domination in society. In effect, taking care of the other is giving this other value to his existence. And, as our author would say, the foundational moment of all ethics lies in the discovery of the one who is not me.

For Dr. Regina Vera Waldow, 'caring' should be understood as a way of being, of being with the other, be it a person, a thing, and so on. Thus, care presents existential characteristics (the "way of being") and relational characteristics (the "being with"); but also contextual, that is, this care presents variations according to the environment and the circumstances in which it is presented. In summary, Vera Waldow proposes seeing care as a way of being, of being with the other, with others, with the world.

To support the above, our author starts from the premise that care is inherent to the human being, and that this is born of a genuine interest in responsibility and love (self-interest, yes, but also for the other), jump to the view that care must be a commitment acquired 
by the simple fact of inhabiting this world; it must be a way of living and cohabiting. Thus, since the nurse is responsible for caring, within nursing care should not only characterize it but becomes part of its mission. Apparently Vera Waldow, ${ }^{4,5}$ [e] n nursing, not every professional that acts in practice, takes care in its real sense. Therapeutic activities, interventions, procedures and techniques are aspects of doing that make up a vast list of "tasks" traditionally called "nursing care". The differentiating element in care is not what is done, but how it is done, that is, the way in which care is carried out is always accompanied by behaviors and attitudes that characterize it: compassion, solidarity, kindness, respect, consideration, Interest, love, and many more.

So, the care provided by the nurse must be human, that is, it must procure the being with whom it interacts and gets involved. When a nurse takes care, a bond is generated that goes beyond the procedure: a relationship is established between two beings who feel. Care is, then, the essence of nursing; nurse-patient dialogue; and an interesting opportunity for a humanized encounter.

What is proposed in this work is that care has an impact, it has a resonance, the word resonance is a term that exists in the Dictionary of the Royal Spanish Academy, ${ }^{6}$ its meanings are related to sound, mechanical, in electricity, in magnetism, in physics, resonance is the result of the coincidence of two frequencies of energy that coincide in amplitude and length. When an object begins to vibrate due to the influence of the other, it is said that there is resonance. ${ }^{7}$ So resonance is prolongation, it is repercussion, it is hypertonia, it is expansion, care necessarily has resonances. The science of nursing focuses on the dimension of caring; we take care of the person in all their biopsycho-social-spiritual dimensions. The nurse is able to understand what happens to the physical, psychological, emotional, beliefs and social environment. The nursing professional is able to use super effective and complex quantum tools to generate resonances.

\section{Methodology}

The type of study that was carried out was qualitative and descriptive, as is well known, this kind of research offers a methodology that allows us to understand the complex world of 'lived experience' from the point of view of those who live $i t ;{ }^{8}$ In addition, it assumes the idea that the subjectivity of people is a part of reality (in fact, this is their field of study); and, finally, it focuses on the study of processes and meanings, as well as on human phenomena and experiences (in effect, it gives importance to the social environment constructed from reality). ${ }^{9}$

However, the type of study was also descriptive because, undoubtedly, this kind of research is adequate not only to document what happens with the phenomenon to be studied, but also helps to better understand the events, behaviors, attitudes and processes most relevant of this phenomenon. Thus, by describing the care that community health nurses provided to pregnant adolescents, it was possible to know the aforementioned behaviors, attitudes and even relevant structures that are presented at the time of providing such care.

\section{Object of study}

It is none other than answering the following question: What care needs does the pregnant adolescent have from the perspective of the nurse in community health?

\section{Population and sample}

The study population that was part of the present investigation was the community health nurses who work in urban and suburban health centers, and who have experience in the care of pregnant adolescents.

\section{Data collection}

The data collection was through the different interviews that were practiced to the community health nurses that attend pregnant teenagers, either in the Health Center where they work or in their home. Participant observation was also practiced with the intention of knowing the environment of the interviewees: type, tone and form of the language and communication used and how to interact with families. Now, the way in which the participant observation was recorded was capturing the narration in field notes, as suggested by Lofland cited in Flick. ${ }^{10}$

Another way of obtaining data was the review of the records and the annotations that the nurses carry out at the end of a consultation or home visit. Of course they were asked for their permission.

\section{Description of data analysis}

Analyzing the data involved, in turn, analyzing the discourse; and for this the 'analysis scheme' proposed by Minayo ${ }^{11}$ was taken into consideration, which is shown below Figure 2.

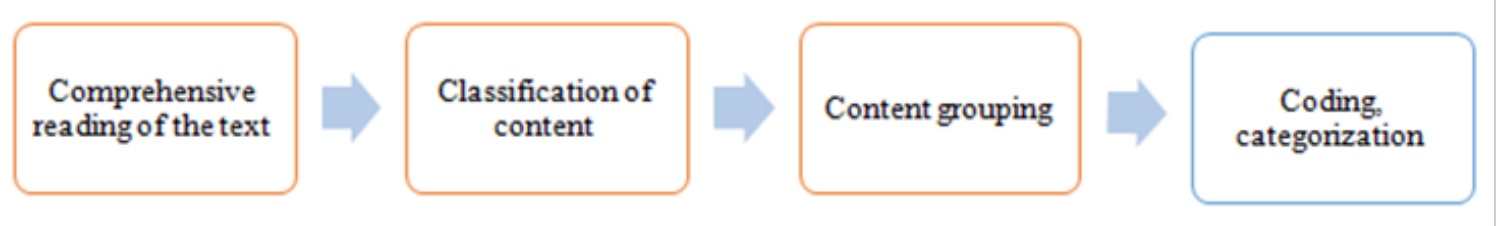

Figure 2 it shows data analysis part.

Now, the mechanics of the coding put into practice in this research was guided in particular by two concepts: "resonances of care" by Boff and "humanized care" by Vera Waldow.

On the other hand, Minayo mentions that the categories of analysis can be defined before undertaking field work, although most of them are general, broad and even abstract. And, as Hernández José Gregorio, et al. ${ }^{12}$ point out in their work, since they are the informants who live the studied experience, they themselves, according to their own vision and perspective of what they have lived, can provide, without being its pretension, categories for a certain investigation. Moreover, they recommend that it be done like this. After the data collection, the researcher must compare these categories already defined with the classification of the data found in the field work. Thus, he could compare the initial categories with those formulated after the field work. Specifically in this investigation, the 'predetermined categories' that were used were, from Boff, "resonance of the care of life". And Vera Waldow, "expressions of humanized care". In this article, the first category is addressed. 


\section{Study limitations}

One of the main limitations of the study was not having access to the relatives of the pregnant adolescents and knowing the opinion about the care provided by the community health nurse, it is unknown if in terms of satisfaction they approve the care provided. And in relation to the categories found, I have not delved into an emerging category found, emancipatory care.

\section{Results}

Once analyzing the speeches of community health nurses who care for pregnant adolescents (AE), in relation to the resonance category of care for life, the following empirical sub categories emerged: love, tenderness, caress, kindness, the compassion. Emergent resonances also emerged: Recognizing (me) in otherness, Listening/conversation as an expression of love and emancipatory care. Dissonances found: Nursing care is only provided if the adolescent is accompanied by a parent or guardian, a situation that limits the pregnant adolescent's participation in the different activities organized by the community nurse (Figure 3).

\begin{tabular}{|l|l|l|l|l|}
\hline \multicolumn{4}{|c|}{ Resonances } \\
\hline $\begin{array}{l}\text { Manifestations of } \\
\text { Love } \\
\text { With the pregnant } \\
\text { teen }\end{array}$ & $\begin{array}{l}\text { Wenderness } \\
\text { Wregnant teen }\end{array}$ & $\begin{array}{l}\text { Caress } \\
\text { With } \\
\text { pregnant teen }\end{array}$ & $\begin{array}{l}\text { Amiability } \\
\text { with teen } \\
\text { with family }\end{array}$ & $\begin{array}{l}\text { Compassion } \\
\text { With teen } \\
\text { With family }\end{array}$ \\
\hline
\end{tabular}

\begin{tabular}{|c|c|c|}
\hline \multicolumn{2}{|r|}{ Emerging resonances } & \\
\hline $\begin{array}{l}\text { Caring (me) and Recognizing } \\
\text { (me) in otherness } \\
\text { The pregnant adolescent is } \\
\text { accepted and known, knowing } \\
\text { and living with other pregnant } \\
\text { teenagers. He recognizes himself } \\
\text { equal to them. By recognizing } \\
\text { the other pregnant adolescent, } \\
\text { she assumes her situation and } \\
\text { identifies herself. }\end{array}$ & $\begin{array}{l}\text { Emancipating care } \\
\text { The nurse takes care of the } \\
\text { pregnant adolescent, respecting } \\
\text { rights, guiding her about rights, } \\
\text { protects her from the family, } \\
\text { offers support to the AE to } \\
\text { make decisions and play an } \\
\text { active roll }\end{array}$ & $\begin{array}{l}\text { Listening/conversation as } \\
\text { an expression of care }\end{array}$ \\
\hline
\end{tabular}

\begin{tabular}{|l|}
\hline Dissonances \\
$\begin{array}{l}\text { Nursing care is only provided if the } \\
\text { adolescent is accompanied by a parent or } \\
\text { guardian. This situation causes that several } \\
\text { adolescents cannot participate in the different } \\
\text { activities of care of the nurse in community } \\
\text { health. }\end{array}$ \\
\hline
\end{tabular}

Figure 3 Empirical categories of care resonances.

\section{Discussion}

Community health nurses who attend AE, on several occasions have difficulties to take care of them and take care of them, these difficulties are mainly of an emotional nature, nurses say that adolescents are fearful, quiet, nervous and most of them cry in the first query. She feels rejected, and usually isolates herself. They are bewildered and suffer emotionally and spiritually. Saying what they feel, expressing them is not always easy, they need to be supported and understood by the nurse so they can do it. From the foregoing, it is important to highlight the attention provided by the nurse, the way of caring and how the process of caring from the perspective of vulnerability is approached, ${ }^{13}$ whose condition makes care necessary, but the moment of caring is established when there is a bond of trust to be caring for the being who cares, for this, the authors mentioned above, emphasize the importance of first showing responsibility, competence, respect and sensibility on the part of the caregiver.
It is important to recognize the $\mathrm{AE}$ as subjects of care with affective needs, common characteristics, as individuals or subjects that differ from others because they are vulnerable to a natural situation (pregnancy) but unexpected for them, a situation that cannot be ignored by the nurse who attends them and observes in them situations like the following:

a. Most of the pregnant teenagers are very shy, they come with shame, with their heads down, they do not want to look, they are sorry, they are afraid, they do not know what awaits them. (E1)

b. They arrive with a lot of fear, with a lot of grief, and they are withdrawn.

c. I realize that they almost do not talk, the look is down, I begin to explain the importance that she has to talk to me, I tell her I do it with the intention of helping her. (E3)

d. They are distressed, the pregnant girl, most of the time is embarrassed, because she says, that she did not expect a pregnancy, another concern they have is that they do not know what will happen to them, both at home as with pregnancy. I try to give them confidence first. (E5)

e. Waldow ${ }^{14}$ mentions that the act of caring has always been a connotation to provide, promote the good to another being, It is therefore a rather peculiar action, the purpose is something or someone who needs the action of care, in nursing being that suffers, that is lacking, vulnerable, requires care. The caregiver responds to a clear manifest need for care.

f. Leonardo Boff ${ }^{15}$ comments that tenderness can and should coexist with the extreme effort for a cause, the relationship of tenderness does not involve anguish because it is free from the search for advantages and domination. The tenderness is the strength of the heart, is the deep desire to share paths. The anguish of the other is my anguish, its success is my success and its salvation or perdition is my salvation and, deep down, not only mine but of all. ${ }^{16,17}$

g. I touch their shoulders, they smile, I touch their hands, I tell them nothing happens, and you and your baby will be fine. Sometimes the girl is very scared, I have to hug them because she cries too much, she is very afraid, then I hug her, I approach her, it's something very nice, with the hug I want to tell you, I support you, you I help... (E6).

h. The humane treatment for me is very important, the greeting is important, I look at them, I tell them to tell me what I can help them or to take care of them, he smiled, he smiled a lot, I ask them how they are ... .Sometimes I make them smile a little. Even sometimes I have given hugs to patients, I won, I gained the momentum. I say words like, do not worry, we'll help you, you're not alone, if you believe in something or someone has faith and comes close to God (E2).

Tenderness is an essential manifestation in the care process that arises when the nurse understands the subject-subject relationship, that is, when it becomes conscious, that it takes care of a person, not a disease, nor an organ, nor an object. When the nurse expresses tenderness to the AE, it will make her feel understood, supported and manage to dissolve her concern. In the testimonies we can see how the nurses care about the pregnant adolescent and try to comfort her. 


\section{Conclusion}

What is concluded in the research is that the pregnant adolescent needs humanized care, of an emotional and personal nature, the pregnant adolescent is in a vulnerable state, has emotional and spiritual suffering (feelings of loneliness, fear, sadness, crying, anguish, isolation, rejection) and at the same time bewilderment due to instability in their family, school and/or work contexts. That is, she does not know how to face the situation of her pregnancy in her family, in her school or in her work area because of what Angustia feels about her present-future.

Thus, a form of care that covers the needs of the dimension of being is humanized care, relying on the resonances of care, understood these, two frequencies of energy that coincide in amplitude and length. As mentioned earlier, the resonances of care are prolongations, repercussions and expansion of the effect that causes care with love, tenderness, patience. The community health nurse cares for the person in various dimensions, biologically, psychologically, socially, spiritually and emotionally, managing to resonate with the patientperson in their care giving comfort and caring for the other.

\section{Acknowledgments}

None.

\section{Conflicts of interest}

The authors report no conflicts of interest.

\section{References}

1. Boff Leonardo. The essential care: ethics of the human, compassion for the earth. Madrid. 2002.

2. Toro-Bernardo. The Ethics of Care Online conference. CREA National Congress. 2013.
3. Maturana H. Language and reality: the origin of the human. Arch Biol Med Exp. 1989;22:77-81.

4. Waldow Vera R. Comprehensive care: Taking care of yourself, the other, the whole. Rev Paraninfo digital. 2012. 15 p.

5. Waldow Vera R. Take care of yourself, take care of the other, take care of everything: implications for health and nursing. 2013;2(1):53-56.

6. The Dictionary of the Spanish language. 23 ed. 2014.

7. Espino Alayo S, Gómez Luján MP. Nursing and its resonances of care in the hospitalized child. Enferm Investig Desarrollo. 2013;11(1):2-18.

8. Minayo Maria Cecilia de Sauzo. The challenge of knowledge. 1997. $227 \mathrm{p}$.

9. Denzin NK, Lincoln S. Strategies of Qualitative Inquiry. 4 ed. Sage publications; 1994. 448 p.

10. Flick Uwe. Introduction to qualitative research. 3rd ed. 2012. 324 p.

11. Minayo Maria Cecilia de Sauzo. Social investigation. Theory, method and creativity. 1993. $108 \mathrm{p}$.

12. Hernández José Gregorio, Herrera Larry, Martínez Ramón Páez, et al. Theory generation seminar: grounded theory. The University of Zulia, Venezuela. 2011.

13. Waldow Vera R, Borges Rosália F. The caregiving process in the vulnerability perspective. Rev. Latino Am. 2008;16(4):765-771.

14. Waldow Vera R. New ideas about care. $A \tilde{N} O .2009 ; 8(1): 85-96$.

15. Boff Leonardo. Tenderness: the sap of love. 2014.

16. Boff Leonardo. The necessary Care. 2012. 172 p.

17. Berenguera A, Fernandez de Sanmamed MJ, Pons M, et al. Escuchar, observar y comprender. 2014. 224 p. 